\title{
Optimal Foraging Theory's Application to Internet Sex Offender Search Behavior: A Theoretical Model for Computer Forensic Investigations
}

Keywords: Computer forensics; Optimal foraging theory; Intemet; Sex offenders

\begin{abstract}
Previous literature involving Optimal Foraging Theory has largely been focused in the biological sciences with only limited studies examining its affect in a criminal context. Those studies have successfully demonstrated foraging pattems in criminals selecting targets for burglary and motor vehicle theft. Evidence from official sources and forensic computing indicates a substantial rise in the number of sexual crimes facilitated by Intemet sexual predators. Understanding the behavior of this population could result in better investigation and prevention methods. This paper presents a mode of Optimal Foraging Theory applied to the behavior of Intemet sexual predators. It draws from the literature in ecology, criminology, Intemet foraging, and sex offender behavior. It also draws on investigations of sex offenders and their behavior in searching for and selecting targets. The result of the disc ussion is a theoretic al fra mework of search behaviour of Intemet sex offenders.
\end{abstract}

\section{Introduction}

According the to the Federal Bureau of Investigation (2013), the Internet has increased access to the population of people sex offenders seek to victimize through solicitations for child pornography and other sex crimes [1]. Prior research on Internet sex offenders has been of limited help to computer forensic investigators, and has focused mainly on exploratory studies examining the characteristics of Internet sex offenders [2-7], their targets [8-10] and what characteristics differentiate between Internet sex offenders and traditional sex offenders [11]. There is an absence of research explaining the search strategies of Internet sex offenders. This paper seeks to aid forensic investigators by providing a blueprint of how Internet sex offenders search the Internet for potential targets. ${ }^{1}$

Previous studies demonstrated that people have certain patterns they use to search for information online [12-14]. The time using these searching strategies, time scanning the information found for answers to queries, and the number of steps taken for searchers to reach pertinent information was found to be significant aspects of Internet information retrieval $[12,15]$. This paper builds a theoretical model to determine if Internet sex offenders also use a specific search strategy when attempting to identify potential targets. Optimal foraging theory is used as a foundation to examine how sex offenders search for pornography or people.

1 For the purposes of this research, a target can be content (pornographic images, videos, etc.), communication (chatting on line), or attempts to make physical contact with a person.

\section{Journal of Forensic Investigation}

\author{
Kyle A. Burgason and Jeffery T. Walker* \\ Department of Criminal Justice, Ross Hall 513,University of \\ Arkansas at Little Rock, Little Rock, AR 72204, USA \\ Address for Correspondence \\ Jeffery T. Walker, PhD, Department of Criminal Justice, Ross Hall \\ 513,University of Arkansas at Little Rock, Little Rock, AR 72204,USA. \\ Tel: (501) 569-3195; Fax: 569-3075; E-mail: jtwalker@ualr.edu \\ Submission: 09 May 2013 \\ Accepted: 29 May 2013 \\ Published: 03 June 2013
}

\section{Optimal Foraging Theory}

Optimal Foraging Theory has been prevalent in ecology and biological literature, having been developed in the work of Emlen [16] and MacArthur and Pianka [17]. The theory was first used to predict foraging behavior of animals utilizing mathematical models [18]. These models were used to predict evolutionary fitness of different species of animals, where fitness is enhanced by those foragers who acquired more food, conserved more time, and managed to avoid risk during foraging $[16,17,19]$.

Optimal Foraging Theory examines four components that are necessary for optimization: An actor, who chooses among alternatives; currency, by which the actor measures costs and benefits; constraints, beyond the actor's control that limits behavior; and a strategy, specifying the actor's range of available options [17,20,21]. An actor will adhere to a specific search strategy within a food patch until the point in time when the energy expended in securing the food outweighs the energy obtained from the food. The currency in the cases of biological foraging refers to the rank of particular resources pursued by an animal. Typical cost/benefit currencies in foraging include calories, nutrients, proteins, and energy [16-18]. The constraints experienced by the actor are both intrinsic and extrinsic and include terrain, travel time, climate, mobility, resource density, as well as abilities and skills of the actor, technology, and knowledge of the environment [19]. The strategy component of optimal foraging theory contains all the decisions and choices available to the actor at a given time while considering degree of risk involved with decisions $[16,19]$.

There are four broad decision categories associated with optimal foraging theory: prey choice and diet breadth, choice of patch type, allocation of time between patches, and patterns of speed and movement within patches [16-18,20,22]. The prey choice and diet breadth category refers to an animal's choice of one type of food over another. It has been found in several studies [23-25] that animals will pass by certain items in search of others that will yield greater energy intake when such items are clumped or available in a patchy manner. When resources are evenly distributed throughout an environment, it is said to be homogeneous, which leads foragers to consume items randomly and exploit resources in proportion to their availability [19]. A forager's diet will be more specialized when high yield food items are readily available and more generalized when high yielding resources are scarce or evenly distributed. Patch choice and 
time allocation, both between and within patches, can be described together. A forager's decision about how long to remain in a particular patch harvesting food before moving to another patch is dependent on the amount of time spent searching for and consuming food relative to the amount of energy gained [17,22]. As long as a patch is providing sufficient food, the forager will remain in the patch. When the time searching exceeds the amount of food obtained, the forager will abandon the patch and search for food elsewhere. A forager's patterns of speed and movement within a patch can be explained with one of two theories. The first theory assumes predators do not detect food at a distance by sight, smell, or other means but rather "meander until prey is encountered and then greatly increase their rate of turning while remaining in the vicinity of the encountered prey" [18]. The second theory assumes predators utilize sight, smell, and other means to detect the location of prey and alter their movements in response to such detection [18]. In regard to the speed of movement within patches, both caloric intake and energetic cost of movement increase with speed of movement, therefore an optimal speed is reached when the net rate of caloric intake reaches a maximum at a speed that depends on the density of the food [26]. At the point in time within the patch when the energy expended in securing the food outweighs the energy obtained from the food, the patch maybe abandoned in what is known as "giving up time" [21,22].

This optimal foraging pattern of food allocation has been identified in various types of biological research on birds [20,22,27]; mammals [23-25]; and insects [28]. In the late 1970s and early 1980s, foraging techniques were identified by Winterhalder [29] in human hunter-gather societies on the boreal forest Cree, by O'Connell and Hawkes [30] on the Alyawara of Australia, and by Hill and Hawkes [31] in four Amazonian Indian populations.

In the 1990s, optimal foraging strategies were applied to people who sought information. Sandstrom [19] identified commonalities between foraging for information and foraging for food: "both resources tend to be unevenly distributed in the environment, uncertainty and risk characterize resource procurement, and all foragers have limited time and experience opportunity costs by choosing to exploit one resource over another."According to Sandstrom, the concepts of biological foraging used by animals searching for food are similar to that of humans searching for information. Conceptually, the optimal forager finds the best solution to the problem of maximizing the rate of net energy returned per effort expended, given the constraints of the environment. Pirolli and Card [32] offer a similar analogous situation to what they identify as the Information Forager:

An office worker or academic researcher facing the recurrent problems of finding task-relevant information. Information flows into the environment to be represented in different types of external media, such as books, manuscripts, or on-line documents. The different information sources (or repositories) will have different profitabilities, in terms of the amount of valuable information returned per unit cost in processing the source. In addition, the different kinds of sources will be distributed in the task environment in different ways. Some will be more prevalent, or less effortful to access, than others [32].

The authors stated that, conceptually, the optimal information forager is one who best solves the problem of maximizing the rate of valuable information gained per unit cost, given the constraints of the task environment. While constraints for foraging animals might be terrain and mobility, for information foraging, constraints include the profitabilities of different sources and the costs of finding and accessing them [32].

Optimal foraging theory in criminal justice has been limited mainly to the study of space and time clusters of burglary [33-38]. Principally, the aim of a foraging burglar is to increase resources while limiting the amount of energy expended and the associated risks of being apprehended. The strategy of a foraging burglar has been identified as targeting dwellings with high relative rewards [38] that are clustered in space, selecting neighboring properties for subsequent burglaries if natural surveillance is limited and adequate escape routes are available $[33,35]$. Targeting homes near those previously burglarized increase efficiency of burglaries, but could lead to a depleted population of targets, resources, and a possible increased risk of apprehension. To account for this, a foraging burglar would move on to investigate the next cluster of homes that present high returns with limited risks of being apprehended. Just as animals return to food plots where resources were once depleted and have grown back, burglars also could return to previously burglarized areas where insurance money was used to recoup the losses, making that cluster of homes again a suitable target for burglary [33]. Johnson and Bowers [35] concluded that foraging burglars target more potentially profitable homes, and seek a different area when the take is low and the risks high. These researchers did not suggest all offenders adopt optimal foraging strategies all the time; but enough offenders do to produce a sufficient proportion of crimes to generative detectable patterns in space-time distributions of crime [33,34].

Originally designed to predict evolutionary fitness of animals Optimal Foraging Theory has been used throughout the biological science since its inception in the 1960s. The preceding paragraphs have demonstrated the range of behaviors OFT has been used to predict. Beginning in the 1960s with animal search strategies for food, the theory evolved to explain insects, and aviary feeding patterns, human hunter-gather strategies, and information seeking, and has even been used to predict residential burglary. We seek to advance the scope of OFT by utilizing its propositions to develop a theoretical framework to explain the search behavior of Internet sex offenders.

\section{Development of a Theoretical Framework of Search Behavior of Internet Sex Offenders}

The primary focus of this paper is to develop a process where optimal foraging theory could be used to explain Internet sex offenders search behavior. To accomplish this task, we take the principles of OFT that have been used to explain animal and human behavior and apply them to the potential behavior of Internet sex offenders. We propose that the concepts and propositions developed in optimal foraging theory will aid computer forensic investigators in examining and explaining the search behavior of Internet sex offenders. The result is a theoretical framework for optimal foraging search behavior described below.

The first component of optimal foraging theory is the actor. The theoretical framework examines the actors' (Internet sex offenders) patterns of searching and how these actors' searches vary depending on what they are seeking. Actors will choose among different alternatives and will vary their search strategy depending what prey they are in search of. For example, how actors search for child pornography 
pictures differs from searches for someone to chat with sexually, and searches for sex videos differ from offenders searching for a target for physical contact. In searching for prey, actors are forced to consider all possible alternatives. Actors must know what currency they are seeking and the constraints, both intrinsic (actors skills and abilities, knowledge of environment, and technology available for use) and extrinsic (distribution of prey, resource density, and travel time) that are associated with a particular prey choice. Optimal foraging models demand that the actor have considerable empirical knowledge of the prey's behavioral repertoire and environment. The seeking behavior of the actors is based on the other three components, discussed below.

Currency is the characteristics of a particular website ${ }^{2}$ that may attract the attention of Internet sex offenders (actors). This component of the framework focuses on what food patches (Internet sites) are more desirable to the actor (Internet sex offender) and provide actors the best chance at acquiring quality food (pornography, chats, or people). For example, websites may contain additional means of contact such as chat rooms, instant messaging services, emails, and bulletin boards that may make the websites more attractive to Internet sex offenders (actors). Prior research $[3,5,10]$ revealed Internet sex offenders frequent websites in an attempt to solicit targets for sexual exploitation. This research found that websites and links that have increased opportunities for interaction between actor and currency are popular places for Internet sex offender searching $[3,5,10]$. In a study of 31 inmates belonging to the Federal Bureau of Prisons' Sex Offender Treatment Program, Malesky [3] found 81\% visited chartrooms for the purposes of meeting targets, $58 \%$ reported either viewing online profiles or bulletin board posting to screen for possible targets. Similar results were found in a study of 129 Internet initiated sex crimes, where $76 \%$ of encounters between offenders and victims began in chartrooms [10].

Prey choice and diet breadth are fundamental themes to optimal foraging theory [16-20,22]; and their abundance or lack thereof influences where and how offenders search. As foraging animals will pass by some patches of food in favor of others that yield a greater source of energy intake [23-25], we expect Internet sex offenders to bypass certain websites and entities in favor of others. In determining what websites warrant further allocation of time, Internet sex offenders must have a plan that guides their search. This plan or strategy for searching takes into account all the available options known to the actor so that the efforts of finding and receiving rewards from their currency are optimized, and outweigh the time and energy spent searching for the currency.

The third component required for foraging to be successful is a strategy. Here we are interested in, not only what brings the Internet sex offender to a particular website, but what characteristics keep the offender on a particular website for extended periods of time. The strategy component of foraging entails three factors of focus in this framework: the content of the websites, the nodes and links within them, and the availability of targets within websites. Important to search strategy is what content the website displays to make offenders use the website to begin searching. For this discussion, the concept within website characteristics refers to the nature of the nodes and links (chat rooms, online profiles, bulletin boards) within each website. In terms of the content of the websites, we explore how sexually explicit

2 For the purposes of this discussion, "website" is any Internet entity that could be used by sex offenders, including websites, chat rooms, news groups, or other accessible content. a website or link within a website must be to hold offenders' attention for increased amounts of time. Just as foraging burglars target more potentially profitable homes that appear in clusters in attractive neighborhoods [35,39], we would expect attractive characteristics that are clustered within a particular patch (website) to gain more attention and time from offenders. As research has shown, sexually themed websites are popular patches for offenders. We know from the biological foraging literature [23-25] that animals will bypass certain food for others that yield a higher energy return. We expect Internet sex offenders to do the same; meaning offenders would bypass certain websites they considered inadequate for optimization in search of those websites where offenders could gain more of the content their desire, thus optimizing their search. With a set strategy guiding their search Internet sex offenders need only minimize their risk of being identified.

The final focus of this framework is constraints facing Internet sex offenders. Important to constraints is what factors influence Internet sex offenders to abandon one website in favor of another. Two key elements here are whether abandonment is due to the risk associated with certain websites (such as being monitored by administrators or guardians or if offenders fear they are being set up by someone claiming to be an underage victim), or if abandonment is due to the depletion of attractive targets. For this framework, the risks of websites and links being monitored by administrators, parents or guardians, and the depletion of attractive targets from the websites and links serve as constraints within the theoretical model. Within this framework, abandonment refers to leaving a particular websites in search of another when the constraints of searching for targets at a particular website outweigh the chances of finding suitable content. This concept was included because it describes the essence optimal foraging theory, maximizing intake while expending the least amount of time and energy doing so, and also avoiding risks. Previous foraging studies have found support for both high risk abandonment [39] and natural depletion of the currency sought [35]. We are interested in assessing what constraints cause Internet sex offenders to quit searching one website or entity in favor of another.

This part of the framework addresses the marginal value theorem [21] of optimal foraging theory. This theorem states that a forager's (Internet sex offender) decision about how long to remain in a particular patch (website) harvesting food (targets) before moving to another patch (website) is dependent on the amount of time spent searching for and consuming food (images, videos, etc.) relative to the amount of energy gained. At the point in time within the patch (website) when the energy expended searching for target sand in securing the food outweighs the energy obtained from the food (successful target acquirement) the patch (website) may be abandoned in what is known as "giving up time" [21,22]. No studies have examined the marginal value theorem as it relates to Internet sex offender search strategy; so again, inferences will be drawn from other studies. Previous studies examining burglary as it relates to optimal foraging theory [35] found that targeting homes near those previously burglarized would indicate a cluster of burglaries spatially; but would lead to a depleted population of targets, resources, and a possible increased risk of apprehension overtime. To account for this, the foraging burglar would move on to investigate the next cluster of homes that present high returns with limited risks of being apprehended. This same principle can be found within biological foraging of animals for food. "Birds that seek food on the ground are 
constantly searching their surroundings for signs of danger... rabbits will constantly move their ears to detect danger on either side of them. Research indicates that animals can recognize an increase in the risk of predation and suitably adjust their behavior to it by showing increased vigilance" [39]. We expect this same behavior of Internet sex offenders; that they will constantly monitor their environment for danger, and will abandon a website if they sense any danger.

In summary, it is expected that Internet sex offenders will follow the behavioral patterns of animals in foraging for food. We believe their patterns will be based on a currency of the targets (images, videos, chat) they seek; and that, like animals that can recognize an increase in the risk of predation [39], Internet sex offenders will abandon a website when the risk of remaining on the website increases. All of these feed into a strategy of foraging of Internet sex offenders that can be used by computer forensics investigators to establish strategies for conducting their forensic examinations.

\section{Theoretical Path Model of Optimal Foraging of Internet Sex Offenders}

A path model of optimal foraging related to internet sex offenders was developed to show how the discussion above fits together and could be used to aid computer forensic examiners in their investigations. This model is shown in Figure 1 and discussed in this section of the paper. The model illustrates how the four elements required for optimal foraging theory come together and provide explanation for Internet sex offender's search behavior. The model is linked back to the biological roots of optimal foraging theory to provide a more thorough theoretical understanding of how each of the elements links together to account for actors search behavior.
As indicated in Figure 1, the form of prey the actors search for (child pornography pictures, child pornography videos, chatting sexually online, or searching for targets to solicit into sexual acts) affects what websites the actor will access, within the limits of constraints. The currency and constraints come together to influence the search behavior of the actor. For example, offenders searching for a website that will allow them the opportunity to solicit a target into sexual acts will generally not stop searching once they find a website with pornographic pictures of children. Having found a website with pornographic pictures, the offender would modify the search strategy to better acquire the sought website, thus affecting search behavior.

The second element required for optimal foraging theory is a currency for which the actor is seeking. For this model, websites and the potential to obtain the desired "food" from them serve as currency. The focus is on what patches (websites) are more desirable, and provide the best chance at acquiring quality food (targets). The more lucrative a particular website is in terms of producing opportunities for high returns of successful targets, the more likely Internet sex offenders are to remain on that website. Previous research has found that websites and online entities such as chat rooms, instant messaging services, emails, and bulletin boards provide increased opportunities for interaction between actor and currency, and are popular places for Internet sex offender searching [3,5,10]. The websites (currency) providing these opportunities for interaction are viewed as an attractive currency to Internet sex offenders. For example, websites containing online profiles of individuals such as Hot-or-Not can be considered a form on currency; however, an online website where communication is available would be considered a higher yielding currency because of the increased rewards (direct sexual chat, real-

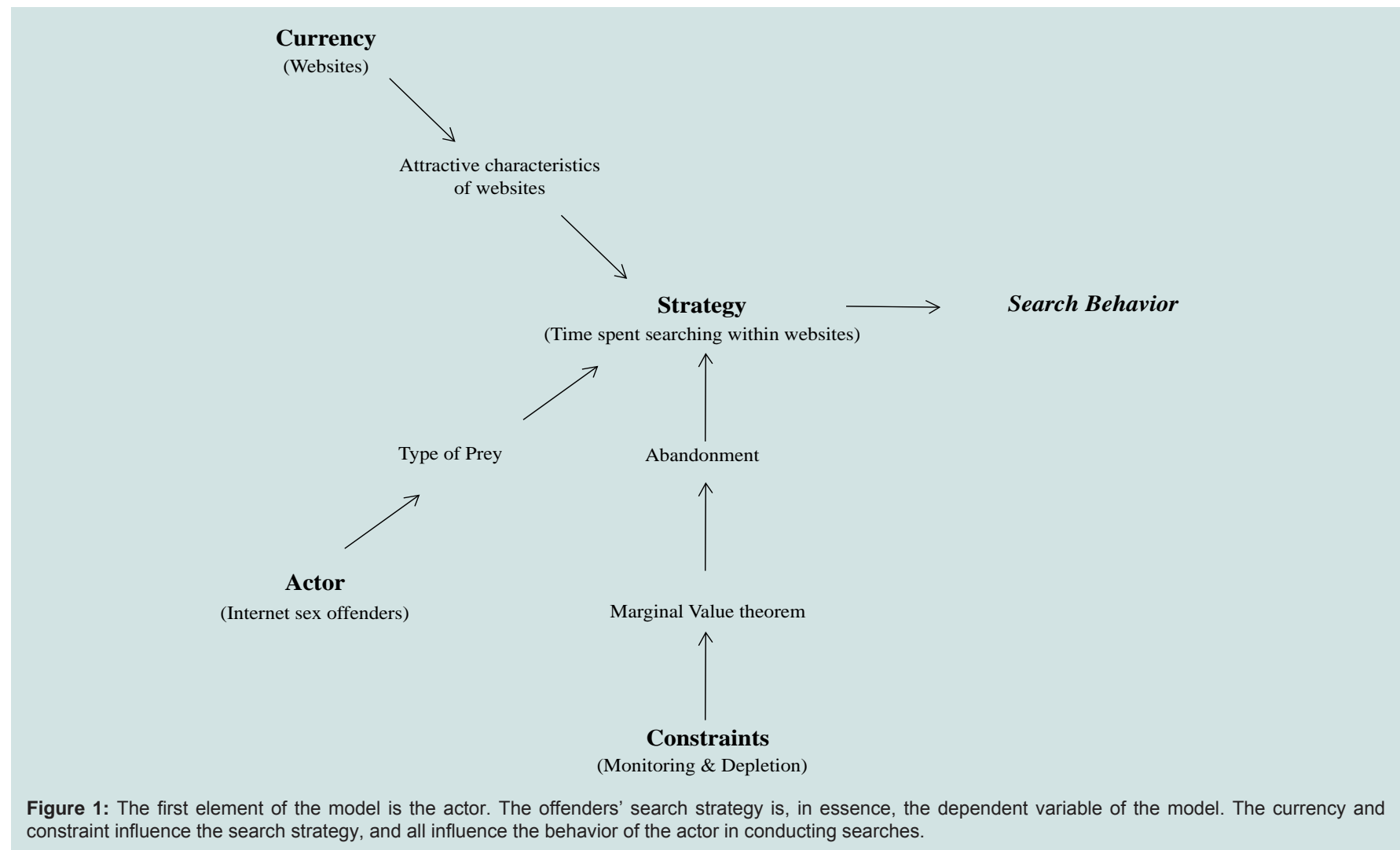


time video, and pictures) available via direct communication. The search for these websites that offer direct communication (currency) becomes part of the strategy of Internet sex offenders. Knowing this currency exists; offenders may alter their searching strategy with the aim of acquiring websites where direct communication is available; thus modifying their search behavior from searching for any website with online profiles, to searching for websites where direct communication is available.

A third element required for optimal foraging theory is the constraints faced by the forager. For this model, the risks of Internet sites being monitored by administrators, parents or guardians, and the depletion of attractive targets from the websites serve as constraints. Websites that have increased levels of monitoring will be avoided or abandoned by foragers for websites where risks of being detected are lessened. For example, chat rooms where typing words of a profane or sexual nature result in users automatically being kicked off the website will likely be avoided completely, or abandoned by offenders once they have been made aware of this constraint. Offenders would modify their search strategy to avoid such websites. When offenders find a website where they can successfully acquire targets, they may return to this website multiple times as they are aware that it yields high returns (successful target acquirement). This can lead to that particular website (patch) becoming depleted of attractive targets (currency). The depletion of the website of attractive targets is a selfinflicted constraint on the part of the offender, causing the offender to abandon the website in search of another that can yield a higher return (successful target acquirement).

The depletion of targets from a website forcing a move to another website is termed the marginal value theorem. This theory states that a forager's (Internet sex offender) decision about how long to remain in a particular patch (website) harvesting food (targets) before moving to another patch (website) is dependent on the amount of time spent searching for and consuming food (targets) relative to the amount of energy gained (targets gained). This depletion becomes an element to be considered in an offender's search strategy because spending too much time within a patch (website) can deplete it of the sought after currency (attractive targets) and thus affect the offender's search behavior.

The final component necessary for optimal foraging theory to be a success for the forager is a strategy. For this model, the strategy component of foraging entails all available options to the forager, including: the content of the websites and the links within them, the availability of targets within websites, the returns (successful acquisition of targets) the forager receives, and avoiding constraints known to the offender. For example, all previous information obtained regarding the actors (Internet sex offenders) and the targets/ prey they are seeking, the currency (websites/targets), whether or not those websites provide the content they are searching for, and avoiding the constraints (monitoring of websites/depletion of targets from websites) that can lead to the abandonment of a website are coupled with the amount of time spent searching between and within websites and the successful rate of returns (target acquisition) to form the search strategy of Internet sex offenders. The elements added by the strategy component include time spent searching and rate of return. Without a successful return on the actors time and energy spent searching for its currency, optimal foraging theory could not exist. The amount of energy taken in by a successful return (in this studies case an acquired target) must be greater than the amount of time and energy spent searching for said currency or the actor will modify the search.

In biological studies a forager's decision about how long to remain in a particular patch harvesting food before moving to another patch is dependent on the amount of time spent searching for and consuming food relative to the amount of energy gained [17,22]. At the point in time within the patch when the energy expended in securing the food outweighs the energy obtained from the food the patch should be abandoned. The strategies for both Internet sex offenders searching for websites and biological foragers searching for food influence the search behavior of the actors. Without any strategy to adhere to when searching for food (websites/targets) actors' search behavior would simply be to wander at random and rely on chance to provide the currency each seeks.

The above illustration and subsequent explanations represent the final theoretical model for this paper. One could argue that there are different ways to arrange the elements within this model. For example, it is possible that effects exist between the actor and currency, or between the actor, the constraints, and search behavior. The placement of the marginal value theorem in the model could also be a point of discussion. One could argue that the marginal value theorem should be placed between the strategy element and the actor. This could be justified within the framework of optimal foraging theory; however, the marginal value theorem relates to optimization, or to when the time spent searching for food (targets) outweighs the energy gained from successful acquisition of targets, which is a constraint faced by foragers.

\section{Optimal Foraging Theory in Policy and Practice}

The four elements required for optimal foraging theory and the concepts identified in the four research questions were structured in a theoretical model that creates a model of how Internet sex offenders search for targets. It is the goal of this theoretical model to aid computer forensic investigators in understanding how each element of optimal foraging theory and the concepts derived from the research questions come together and form a blueprint of the search behavior of Internet sex offenders. The step-by-step model and subsequent explanations take the reader through the theoretical process necessary for a comprehensive understanding of optimal foraging theory's application to Internet sex offender search behavior.

While some forensic investigators may be able to build a case based on a few EnCase searches and a dump of images, videos, and communication, other cases are more complicated and require a more in-depth investigation. Being able to follow an offender from one website to another can aid in establishing timelines of events and in developing profiles, motives, and establishing behavior of the offender. This can aid greatly in complex investigations and prosecutions.

Perhaps more importantly, investigators can use this information to track how offenders use the Internet for elicit purposes. Proactive investigations can benefit from knowing what attracts offenders to particular websites so they can build better monitored sites. They can also use this information to develop proactive investigations and make offenders produce more evidence through their actions that can be used in prosecutions.

Future research needs to be undertaken applying the principles outlined in this paper to computer forensic examinations. A non- 
Citation: Burgason KA, Walker JT. Optimal Foraging Theory's Application to Internet Sex Offender Search Behavior: A Theoretical Model for Computer Forensic Investigations. J Forensic Investigation. 2013;1(1): 6.

random sample of child pornography cases were examined with these methods, and OFT was found to be useful in establishing the behavior of the offender. The principles of OFT need to be further tested, however, with a much larger number and variety of cases to ensure it is viable as an investigative tool. For example, all cases in a state crime lab could be examined (perhaps separately from the legal computer forensic investigation) to determine if the principles of OFT outlined here apply to those cases. It is expected some modification to the discussion here will occur in the larger examination; but it is also expected that the principles of OFT outlined herein will hold and will be useful to investigators.

\section{References}

1. Federal Bureau of Investigation (2013) Violent crimes against children

2. Wolak J, Finkelhor D, Mitchell KJ, Ybarra ML (2008) Online "predators" and their victims: Myths, realities and implications for prevention and treatment. Am Psychol 63: 111-128.

3. Malesky LA Jr. (2007) Predatory online behavior: Modus operandi of convicted sex offenders in identifying potential victims and contacting minors over the internet. J Child Sex Abus 16: 23-32.

4. Webb L, Craissati J, Keen S (2007) Characteristics of internet child pornography offenders: A comparison with child molesters. Sex Abuse 19: 449-465

5. Young K (2005) Profiling online sex offenders, cyber-predators, and pedophiles. Journal of Behavioral Profiling 5: 1-18.

6. Burke A, Sowerbutts S, Blundell B, Sherry M (2001) Child pornography and the Internet: Policing and treatment issues.Psychiatry. Psychology and Law 9: $79-84$

7. Cooper Al, Scherer CR, Boies SC, Gordon BL (1999) Sexuality on the Interne from sexual exploration to pathological expression. Professional Psychology: Research and Practice 30: 154-164

8. Marcum CD (2007) Interpreting the intentions of internet predators: An examination of online predatory behavior. J Child Sex Abus 16: 99-114.

9. Beebe TJ, Asche SE, Harrison PA, Quinlan KB (2004) Heightened vulnerability and increased risk-taking among adolescent chat room users: results from a statewide school survey. J Adolesc Health 35: 116-123.

10. Wolak J, Finkelhor D, Mitchell KJ (2004) Internet-initiated sex crimes against minors: Implications for prevention based on findings from a national study. $J$ Adolesc Health 35: 424.e11-20.

11. Seto MC, Wood JM, Babchishin KM, Flynn S (2012) Online solicitation offenders are different from child pornography offenders and lower risk contact sexual offenders. Law Hum Behav 36: 320-330.

12. Nachmias R, Gilad A (2002) Needle in a haystack: Searching for information on the worldwide web. Journal of Research on Technology in Education 34: 475-486.

13. Slone DJ (2003) Internet search approaches: The influence of age, search goals, and experience. Library and Information Science Research 25: 403418

14. Thatcher A (2006) Information-seeking behaviors and cognitive search strategies in different search tasks on the www. International Journal of Industrial Ergonomics 36: 1055-1068.

15. Walraven A, Brand-Guwel S, Boshuizen HPA (2009) How students evaluate information and sources when searching the world wide web for information. Computers and Education 52: 234-246.

16. Emlen JM (1966) The role of time and energy in food preference. The American Naturalist100: 611-617.

17. MacArthur RH, Pianka ER (1966) On optimal use of patchy environment. The
American Naturalist. 100: 603-609.

18. Pyke GH, Pulliam R, Charnov EL (1977) Optimal foraging: A selective review of theory and tests. The Quarterly Review of Biology 52: 137-154.

19. Sandstrom PE (1994) An optimal foraging approach to information seeking and use. The Library Quarterly 64: 414-449.

20. Smith EA (1983) Anthropological applications of optimal foraging theory: A critical review. Current Anthropology 24: 625-651.

21. Charnov EL (1976) Optimal foraging, the marginal value theorem. Theoretica Population Biology 9: 129-136.

22. Wellborn GA (2000) Testing concepts of animal foraging behavior. The American Biology Teacher 62: 46-50.

23. Lewis AR (1980) Patch use by grey squirrels and optimal foraging. Ecology 6 1371- 1379.

24. Langvatn R, Hanley TA (1993) Feeding-patch choice by red deer in relation to foraging efficiency. Oecology 95: 164-170.

25. Sayers K, Norconk MA, Conklin-Brittain NL (2010) Optimal foraging on the roof of the world: Himalayan langurs and the classical prey model. American Journal of Physical Anthropology 141: 337-357.

26. Ware DM (1975) Growth, metabolism, and optimal swimming speed of a pelagic fish. Journal of the Fisheries Research Board of Canada 32: 33-41.

27. Krebs JR, MacRoberts MR, Cullen JM (1972) Flocking and feeding in the Great Tit, Parus major, An experimental study. International Journal of Avian Science 114: 507-530.

28. Dixon AFG (1959) An experimental study of the searching behavior of the predatory coccinellid beetle adaliadecempunctata. Journal of Animal Ecology 28: $259-281$

29. Winterhalder B, Smith EA (1981) Hunter-Gatherer Foraging Strategies: Ethnographic and Archeological analysis. University of Chicago Press, Chicago.

30. O'Connell JF, Hawkes K (1981) Alyawara Plant Use and Optima ForagingTheory. Pp. 99-125 in Hunter-Gatherer Foraging Strategies (ed. by Bruce Winterhalder and Eric A. Smith). University of Chicago Press, Chicago.

31. Hill K, Hawkes K (1983) Neotropical Hunting among the Ache of Eastern Paraguay. In Adaptive Responses of Native Amazonians, R. Hames and W. Vickers (Eds.). Academic Press, New York

32. Pirolli P, Card S (1999) Information foraging. Psychological Review 106: 634 675.

33. Johnson SD, Summers L, Pease K (2009) Offender as forager? A direct test of the boost account of victimization. J Quant Criminol 25: 181-200.

34. Ratcliffe JH (2006) A temporal constraint theory to explain opportuiy-based spatial offending patterns. Journal of Research in Crime and Delinquency 43: 261-291.

35. Johnson SD, Bowers KJ (2004) The stability of space-time clusters of burglary. The British Journal of Criminology 44: 55-65.

36. Martin D (2002) Spatial patterns in residential burglary: Assessing the effect of neighborhood social capital. Journal of Contemporary Criminal Justice 18: 132-146.

37. Groff ER, LaVigne N (2001) Mapping an opportunity surface of residential Burglary. Journal of Research in Crime and Delinquency 38: 257-278.

38. Hakin S, Rengert GF, Shachmurove Y (2001) Target search of burglaries: A revised economic model. Papers in Regional Science 80: 121-137.

39. Bernasco W (2009) Foraging strategies of homo criminals: Lessons from behavioral ecology. Crime Patterns and Analysis 2: 5-16.

Copyright: (c) 2013 Burgason KA, et al. This is an open access article distributed under the Creative Commons Attribution License, which permits unrestricted use, distribution, and reproduction in any medium, provided the original work is properly cited. 